\title{
DEFICIÊNCIA E TRABALHO NO SETOR INFORMAL: CONSIDERAÇÕES SOBRE PROCESSOS DE INCLUSÃO E EXCLUSÃO SOCIAL
}

Maria Cristina Tissi*

RESUMO: Este estudo abordou a condição de trabalho com deficiência no comércio ambulante de São Paulo, enquanto vivência de processos de exclusão e, paradoxalmente, de inclusão social. $O$ trabalho é concebido pelos ambulantes como elemento que proporciona relacionamentos sociais e confere dignidade e respeito na rede de relações das próprias vidas, mas o plano da sociabilidade, porém, mostra-se contraditório. No ponto de vista do processo de trabalho, a atuação no comércio ambulante revela traços de degradação moral e política; a permanência de um esquema de corrupção, a imposição da subordinação, etc., expressam uma exclusão social, mas os vendedores ambulantes com deficiência não podem ser considerados excluídos. É mais apropriado considerar que aproximam-se da zona de vulnerabilidade, caracterizada por Castel pela instabilidade ocupacional e relacional.

PALAVRAS-CHAVE: deficiência, trabalho, setor informal, inclusão social, exclusão social

* Centro de Docência e Pesquisa em Terapia Ocupacional - Faculdade de Medicina da Universidade de São Paulo 
A temática da deficiência no espaço urbano aponta para aspectos que impedem ou dificultam a acessibilidade, gerando condições de exclusão. Ênfase tem sido dada às barreiras ambientais, geográficas e arquitetônicas, mas sabe-se o problema do acesso a bens de consumo coletivo diz respeito a múltiplos aspectos que se desenrolam nos campos da saúde, educação, cultura, lazer e trabalho.

Com relação ao acesso ao trabalho, temas como revolução tecnológica, desemprego, periferização da pobreza e da deficiência se articulam à configuração e gestão do espaço urbano. A análise das condições de trabalho de pessoas com deficiências no comércio ambulante na cidade de São Paulo ressalta aspectos que dizem respeito à gestão do espaço urbano e ao papel do poder público enquanto mediador de interesses de diferentes segmentos sociais. É nesta perspectiva que a inserção no comércio ambulante revela de forma mais contundente os processos excludentes que se operam em seu interior.

Qualificado como setor informal da economia, o comércio ambulante ocorre nos interstícios da produção capitalista sendo forma de escoamento de bens e de fomento a outras atividades produtivas. Constitui-se portanto como modalidade de integração econômica, estando submetido aos movimentos do capital que cria seu espaço e pode destruí-lo (CACCIAMALI, 1983;S/D).

Buscando dar conta dos movimentos de exclusão e reinclusão próprios da sociedade capitalista, José de Souza Martins (1997) adota a expressão inclusão precária para denominar - formas comumente chamadas de exclusão social. A reinclusão pode se dar num plano econômico, servindo à subsistência, mas não se realizar no plano social, podendo haver a integração econômica ao lado da desintegração moral e social (MARTINS, 1997).

O processo e as condições de trabalho no comércio ambulante atestam que inclusão e exclusão não são pólos antagônicos. Os ambulantes fazem parte de um processo produtivo e, mais do que isso, de um processo social que se desdobra em múltiplas relações e dimensões sociais. A inserção no trabalho promove a integração econômica, permitindo renda e possibilitando a subsistência própria e da família, o acesso ao consumo e a recursos materiais. À integração econômica imbrincam-se ganhos no plano simbólico, como são os valores éticos e morais associados à inserção no trabalho e aos seus resultados materiais, expressos na dignidade por constituir família e opor-se aos "vagabundos, aos que não têm disposição ou capacidade para o trabalho e aos mendigos”, categorias ligadas, nas suas representações, à desonestidade.

No plano da sociabilidade - integração/ desintegração moral e social, a inserção no trabalho promove a ampliação das relações sociais, pessoais ou comerciais, sejam boas 
ou ruins, fazendo oposição ao isolamento. Numa outra perspectiva, permite aos ambulantes com deficiências superar qualidades socialmente desvalorizadas atribuídas às pessoas com deficiência, alcançando condições materiais que favorecem a independência de terceiros para a sobrevivência e o estabelecimento de vínculos sociais, opondo-se assim ao isolamento, à dependência, à pobreza e ao abandono. São dadas, ainda, condições que lhes permitem confrontar as representações sociais das deficiências, num processo de flexibilização dos parâmetros culturais de normalidade, em que refazem suas concepções acerca da deficiência e de si mesmos.

Neste sentido, os vendedores ambulantes inserem-se numa extensa trama de trocas sociais de diversos tipos e qualidades, o que não permite qualificá-lo somente como espaço de exclusão. É buscando integrar-se economicamente, buscando meios de sobrevivência e reproduzindo-se como trabalhadores que acessaram o comércio ambulante; constituem-se na identidade de trabalhadores e provedores da família, o que Ihes confere a dignidade e o respeito na rede de relações pessoais, incluindo familiares, amigos, vizinhos. Ainda que dentro de limites estreitos, a inserção no comércio ambulante é possibilidade de autonomia, de decisão e gestão das próprias vidas.

Por outro lado há processos excludentes que se manifestam no seu interior, vinculados a um processo mais geral desencadeado na sociedade, que denominamos exclusão social. No sentido dado por Aldaíza Sposati (1996), a exclusão é um processo social, uma lógica presente nas várias formas de relações econômicas, sociais, culturais, políticas e que inclui a subalternidade, a não equidade, a não acessibilidade, a não representação pública. A análise do processo de trabalho no comércio ambulante ilustra como se dão estes processos de exclusão.

\section{TRAJETÓRIAS DE TRABALHO}

O acesso ao comércio ambulante é precedido por trajetórias ocupacionais que revelam que já antes da deficiência a inserção no trabalho era precária. Trabalhadores manuais nos setores primário e terciário, sem vínculo empregatício, sem cobertura da seguridade social e com baixo grau de escolaridade, a deficiência, muitas vezes ocorrida na fase produtiva, representou um marco implicando na reorganização da trajetória ocupacional.

A inserção no comércio ambulante, já na condição de pessoas com deficiências, é precedida por tentativas de inserção como trabalhadores autônomos mais integrados ou assalariados. São períodos marcados pela busca de integração econômica, dificuldades e resistências. As dificuldades para o uso dos transportes coletivos e as barreiras 
discriminatórias impostas pelas empresas, aliadas à baixa escolaridade e, às vezes, à aposentadoria por invalidez, foram impedimentos para o trabalho assalariado. As dificuldades de capital, a ausência de profissão e a baixa escolaridade conduziram ao comércio ambulante, quase invariavelmente, como única alternativa, concebido como oportunidade de integração econômica, de sobrevivência e manutenção de suas famílias, de socialização, contra o isolamento e, por vezes, a mendicância.

Ao contrário das concepções que sugerem facilidade de acesso ao trabalho por conta própria, a inserção no comércio ambulante apresentou dificuldades, que permanecem no cotidiano do trabalho: legalização junto ao poder público municipal, problemas com a fiscalização e com outros ambulantes, dificuldades relacionadas à organização do processo de trabalho derivadas das incapacidades físicas.

\section{ORGANIZAÇÃO DO TRABALHO NO DIA-A-DIA}

A jornada de trabalho varia entre seis e doze horas, podendo estender-se ao período noturno para alguns. Ainda que haja uma rotina de horários que se busca seguir todos os dias, há variações determinadas, em geral, pelas condições climáticas que por sua vez influem no movimento das vendas. O fluxo de vendas não é regular. Além das variações climáticas, não há horários previsíveis de maior ou menor fluxo de clientela. Esta imprevisibilidade gera tensão, pois nunca se sabe ao certo se é hora de encerrar ou se vale a pena ficar mais um pouco. A conseqüente instabilidade em relação aos rendimentos traz insegurança quanto ao pagamento das dívidas junto a fornecedores, ampliada pela presença da deficiência que se constitui em obstáculo e razão de resistência por parte dos fornecedores para a oferecer crédito.

A irregularidade do trabalho é também determinada pela conjuntura em relação à fiscalização e às pressões da Prefeitura, havendo alternância entre repressão e tolerância ao comércio ambulante.

O processo de trabalho organiza-se em compra, definição de preços e preparação de mercadorias, organização, montagem e desmontagem da banca, vendas, guarda dos volumes, pagamento de ajudantes ou vigias, troca de mercadorias com outros ambulantes. A aquisição de mercadorias, com freqüência, é realizada através de terceiros ou em estabelecimentos próximos ao ponto, em decorrência das dificuldades de locomoção, o que eleva os custos. Recursos de suporte, como são os vigias durante a noite ou os guardavolumes, representam também aumento dos custos, somando-se aos gastos com alimentação e transporte. Freqüentemente, em função das barreiras arquitetônicas ou da 
discriminação sofrida por funcionários das empresas de ônibus e metrô, optam por utilizarse de táxi ou manter carro próprio. Há ainda o pagamento de taxas para a Prefeitura e para associações de ambulantes.

Há diferentes tipos de inserção no comércio ambulante, de acordo com a rentabilidade obtida, grau de integração com o setor formal, e tipo de atuação: como "testa de ferro" (na condição de deter legalmente o ponto mas ceder seu domínio a um terceiro), como ajudante ou proprietário, e existe a possibilidade de alugar o próprio ponto e atuar clandestinamente em outro. Também caracterizando a heterogeneidade da inserção são as qualidades da relação estabelecida com o poder público, segundo a condição de posse da licença ou clandestinidade, o que pode conformar diferentes relações com a fiscalização.

A subordinação do comércio ambulante aos movimentos do capital é percebida através da flutuação dos níveis de renda da população, dos custos da matéria-prima e dos níveis de desemprego que geram inchamento e aumento da concorrência.

O trabalho no comércio ambulante é concebido como cansativo e humilhante. A irregularidade dos rendimentos e o sentimento de instabilidade e insegurança da ocupação provocada pelas pressões do poder público e de outros ambulantes forçando a entrada no mesmo e ampliando a concorrência fazem com que o desgaste além de físico seja mental.

Nem a entrada nem a permanência no comércio ambulante são fáceis. A expectativa quase sempre é de abrir um estabelecimento comercial em ponto fixo. Não sendo possível, cada um busca através de arranjos superar as dificuldades. Adquirir mercadorias de terceiros, nas poucas lojas que oferecem crédito ou em estabelecimentos próximos à banca, contar com ajuda de familiares para as compras e locomoção ou com auxílio de outros ambulantes para montar e desmontar a banca, alugar o ponto e atuar clandestinamente para aumentar a renda, usar táxi ao invés de transportes coletivos de massa e contribuir para a corrupção dos fiscais são alguns dos arranjos. Outras estratégias são desenvolvidas no campo das relações pessoais facilitando o relacionamento com fiscais, comerciantes e demais ambulantes.

O que aparentemente parece ser uma ocupação simples e viável para ser realizada por pessoas com deficiências é um processo com grande complexidade que requer possibilidades de transporte, de negociação com fornecedores e ajudantes informais, de capital. Mas, são as relações conflitivas com o poder público que representam maior degradação moral.

Na conjuntura estudada a Prefeitura vinha encaminhando a implantação de bolsões para a concentração dos vendedores ambulantes da região central da cidade, restringindo 
o comércio de rua. Restrito aos bolsões o comércio ambulante seria descaracterizado, já que é tipicamente um comércio de calçadas servindo-se de uma clientela que se dirige ocasionalmente aos vendedores ambulantes enquanto se desloca para outras atividades ou compras nos estabelecimentos comerciais. Desenvolve-se, pois, nos interstícios abertos pelo comércio formal. A transferência para bolsões representa ameaça de perda da possibilidade de trabalho.

Este processo desencadeado pelo pode público municipal é concebido pelos vendedores ambulantes como "descaso" do poder público, ou um "jogo" ligado ao esquema de corrupção. Neste esquema, ambulantes não regulamentados, sem licença, pagariam propina pela uso de pontos, tendo prioridade na escolha dos mais rentáveis, restando ao regulamentados os pontos pior localizados. A restruturação do comércio ambulante com a criação de bolsões serviria para inaugurar uma nova distribuição e venda irregular de pontos.

Aqui entram em confrontos interesses que só indiretamente podem ser referidos ao grande capital. É possível que a ampliação do comércio ambulante provocada pelo aumento do desemprego torne visível contradições que não se conciliam com a perspectiva de uma cidade que pretende ser urbanizada, símbolo do desenvolvimento econômico e social. Está em ação um processo desencadeado pelo poder público municipal que pode envolver interesses eleitorais imediatos mas, mais do que isso, no qual se estabelece a recusa de seu papel de mediação de interesses, representando uma atitude de menosprezo perante um segmento desprovido de recursos econômicos e políticos que permitam poder de negociação. Ao que tudo indica, a ação da prefeitura em acabar com o comércio de rua na região central da cidade está subordinada a interesses de comerciantes, organizados em associação que tem por objetivo a revalorização da região e, provavelmente, a especulação imobiliária.

Esta compreensão encontra-se fragmentada entre os ambulantes, os interesses envolvidos não são claramente percebidos. As justificativas oficiais - desorganização, incômodo aos pedestres e lojistas, sujeira, tão preconizados na mídia, são reproduzidas entre eles. A atitude é de conformismo, de quem se vê impossibilitado de opor resistência. A constante instabilidade, assim como a tensão vivida na relação com os fiscais, perpetuandose no comércio ambulante, são percebidas como adversidades, quase como as variações climáticas.

O aspecto da corrupção que envolve o comércio ambulante, ao contrário, é percebido pelos ambulantes e reconhecido como de conhecimento público de administradores regionais, prefeitos, vereadores, imprensa e do público em geral. A irregularidade da distribuição dos pontos nas ruas é notória, contrariando a legislação que a regulamenta e tornando evidente 
sua ilegalidade. A permanência de um esquema de corrupção, mesmo sob o conhecimento de autoridades públicas e da imprensa, a imposição de subordinação - sob ameaça ou concretização de violência -, o não cumprimento pelo poder público da legislação pertinente ao comércio ambulante, são formas que acompanham este trabalho, agravadas pelo controle repressivo sobre o mesmo na atual gestão municipal.

Neste processo cíclico de repressão/tolerância ao comércio ambulante vários são os agentes que se apresentam no cenário, entre administradores regionais, prefeitos e, principalmente, fiscais da prefeitura. O não cumprimento integral pelo poder público da legislação que regulamenta a ocupação, que destina dois terços das áreas reservadas ao comércio ambulante a pessoas com deficiências ou idosas, opõe obstáculos para a obtenção de licença. A não adequação dos pontos às suas necessidades específicas relacionadas à locomoção, por exemplo, também contribui para que muitos atuem na clandestinidade. Assim, os relacionamentos com os fiscais são quase sempre conflitivos, incertos, obscuros, ensejando formas de corrupção e autoritarismo. Inspiram medo, silêncio e a sensação de que "não é possível ser muito honesto para atuar no comércio ambulante" (TISSI, 1998).

A posse de licença não atenua necessariamente os conflitos com fiscais: tomamse mercadorias, propinas, há represálias e, às vezes, tolerância para com as pessoas com deficiências. Os conflitos podem estender-se à Guarda Civil Metropolitana, agentes da Polícia Federal ou Civil e até mesmo de transito.

Para reclamar seus direitos consideram que é preciso coragem, tempo, advogado, e há o medo de represálias. Muitos preferem enfrentar sozinhos a situação, arranjando-se como possível. Os direitos, ainda que reconhecidos, são considerados inacessíveis neste campo onde "todo mundo sabe, mas ninguém vê" (TISSI, 1998).

O relacionamentos com outros ambulantes são distantes, teme-se ameaças já que são concebidos como participantes do esquema de corrupção e adquirem poder de coação sobre os demais ambulantes.

A ausência de representatividade de seus interesses, manifesta na falta de legitimidade que os entrevistados percebem nos organismos representativos, sejam sindicatos, associações ou vereadores, a falta de visibilidade pública de sua condição, o não acesso a direitos são indicadores de que a inclusão realizada é precária, precariedade menos da ordem material do que política e moral.

Além destes aspectos, o trabalho no comércio ambulante é considerado não valorizado socialmente. "Maloqueiros, bandidos, ladrões, vagabundos" (TISSI, 1998) são 
alguns dos adjetivos comumente adotados pelos pedestres que se vêem prejudicados pelas bancas que obstruem a passagem. Contraditoriamente, a inserção no trabalho é valorizada como ética organizadora que permite constituir família, prover estudo para os filhos, uma "forma honesta de ganhar a vida". A família organizada e o trabalho respeitável legitimam a existência social do trabalhador fora do qual trabalho e vadiagem se confundem (TELLES, 1990).

O comércio ambulante comporta a contradição de ser uma modalidade de ocupação legalizada - regulamentada pelo poder público - que por suas características inerentes e mercadorias comercializadas compõe a economia invisível, persistindo sempre um caráter de ilegalidade que se amplia com a condição de clandestinidade e confunde-se com as imagens de traficantes e ladrões. A ocupação é percebida como inferior e desprovida de poder, o qual seria detido pelos assalariados, por aqueles que têm profissão e escolarização.

\section{INCLUSÃO PRECÁRIA E VULNERABILIDADE}

As situações que envolvem precariedade, que, como visto, nem sempre é econômica, expressam os movimentos do capital que resultam em processos excludentes, mas também revelam os movimentos realizados por atores sociais em busca da sobrevivência - integração econômica - e da inserção numa rede relacional. Há um sujeito na situação, parece indicar o José de Souza Martins trazendo a análise para a esfera dos atores sociais:

“(...) rigorosamente falando, não existe exclusão: existe contradição, existem vítimas de processos sociais, políticos e econômicos excludentes; existe o conflito pelo qual a vítima dos processos excludentes proclama seu inconformismo, seu malestar, sua revolta, sua esperança, sua força reivindicativa e sua reivindicação corrosiva" (MARTINS, 1997, p.14).

Nesta direção, são várias as análise que associam outros elementos, além dos econômicos, à compreensão do fenômeno da exclusão social.

CASTEL (1994) dá ênfase, na abordagem das situações de privação, aos aspectos relativos à sociabilidade. Considera que não somente a insuficiência de recursos materiais ameaçam as populações vulneráveis, mas também a labilidade de seu tecido relacional as fragiliza. A privação comportaria, pois, a dissociação do vínculo social - desfiliação.

Sugere encarar as situações de privação como "um efeito na conjunção de dois vetores: um eixo de integração/ não integração pelo trabalho e um eixo de inserção/ 
não inserção em uma sociabilidade sócio-familiar" (CASTEL,1994, p.23). O recorte dos dois eixos, da integração no trabalho e da inserção relacional, configuram, para o autor, zonas diferentes do espaço social. A zona de integração supõe garantias de trabalho permanente e a possibilidade de mobilizar suportes relacionais sólidos; a zona de vulnerabilidade é aquela onde o eixo do trabalho é precário e as redes relacionais frágeis; a zona de exclusão - desfiliação, por sua vez, conjuga ausência de trabalho e isolamento social.

O comércio ambulante mostrou ser um espaço de conflitos, de ausência de direitos e de cumprimento às leis. Espaço de violência e tirania, de ausência de representatividade e de visibilidade de interesses e, também, de ausência de participação na elaboração de políticas. É, nestas condições, espaço de medo, de insegurança, de incertezas, lugar de calar-se, de conformar-se, de arranjar-se como possível.

Vários elementos fazem com que o trabalho no comércio ambulante seja considerado excludente. Mas, também é espaço de inclusão. O que se coloca em questão, portanto, são os elementos que concorrem na qualidade da inclusão realizada sob a exclusão social.

Os entrevistados, como visto, não podem ser considerados excluídos. Tampouco constituiriam a zona de desfiliação. Talvez seja mais apropriado considerar que aproximam-se da denominada, por CASTEL (1996), zona de vulnerabilidade: instabilidade ocupacional e relacional. A instabilidade ocupacional vivida no comércio ambulante é evidente na situação estudada, assim como é contraditório o eixo da sociabilidade/relacional. Contudo, os entrevistados revelam dinamismo frente às adversidades, mostrando capacidades para adaptar-se, para elaborar estratégias de sobrevivência, para formular arranjos e re-arranjos, para recompor concepções, ainda que não se apresentem coletivamente dando visibilidade aos seus interesses no confronto de classes.

Frente à ameaça de não trabalho, novas alternativas de integração econômica são configuradas pelos entrevistados. Por outro lado, tomando o campo da sociabilidade, ainda que as relações estabelecidas através do trabalho sejam frágeis, assim como as redes de solidariedade presentes na sociedade, nada sugere que se coloquem sob risco de isolamento, a menos que houvessem rupturas significativas (e com tendência a se prolongarem) nas várias dimensões resultantes do trabalho.

Isso não significa que a ameaça de desfiliação seja irreal: o tipo de inserção social, pelas várias razões já analisadas, submete-os, enquanto segmento social, à precariedade e aos seus riscos. 


\title{
REFERÊNCIAS BIBLIOGRÁFICAS
}

CACCIAMALI, M.C. As economias informal e submersa: conceitos e distribuição de renda. s.d. 20p. (Trab. Doc. FEA)

CACCIAMALI, M.C. Setor informal urbano e formas de participação na produção. São Paulo, IPE/USP. Ensaios econômicos, 26, 1983.

CASTEL, R. Da indigência à exclusão, a desfiliação. Precariedade do trabalho e vulnerabilidade relacional. In: LANCETTI, A.(org.). Saúdeloucura, 4. São Paulo, Hucitec, 1994.

MARTINS, J. de S. Exclusão social e a nova desigualdade. Paulus, 1997.

SPOSATI, A. Mapa da exclusão/inclusão na cidade de São Paulo. São Paulo, EDUC, 1996.

TELLES, V. da S. A pobreza como condição de vida. Família, trabalho e direitos entre as classes trabalhadoras urbanas. São Paulo em perspectiva, 4 (2): 37-45, abril/ junho, 1990.

TISSI, M.C. Deficiência e trabalho no setor informal. Campinas, 1998. [Dissertação de Mestrado - Faculdade de Ciências Médicas, UNICAMP].

\section{DISABILITY AND WORK IN THE INFORMAL SECTOR: CONSIDERATION OF INCLUSION AND EXCLUSION PROCESSES}

\begin{abstract}
SUMMARY: This study addressed work conditions and disability in street vendor activity in São Paulo as experience of exclusion processes and, paradoxically, of social inclusion. Work is considered by street vendors the element providing social relationships and dignity and respect in the social network, within strict limits, it also means opportunity for autonomy, decision, management of their own lives. However, as to sociability it is controversial. In respect to work process, street vendor activity shows signs of moral and political degradation. Maintenance of a corruption scheme, imposition of subordination, etc., express social exclusion, but the disabled street vendors could not be considered as excluded. It is more appropriate to consider them as closer to the vulnerability zone, characterized by occupational and relational unstability, according to Castel.
\end{abstract}

KEY WORDS: disability, work, informal sector, social inclusion, social exclusion 